\title{
PftetQ and pfmdt copy numbers as predictive molecular markers of decreased ex vivo doxycycline susceptibility in imported Plasmodium falciparum malaria
}

Tiphaine Gaillard ${ }^{1,2,3}$, Sébastien Briolant ${ }^{1,2}$, Sandrine Houzé ${ }^{4,5,6}$, Meïli Baragatti ${ }^{7}$, Nathalie Wurtz ${ }^{1,2}$, Véronique Hubert ${ }^{4,6}$, Morgane Lavina ${ }^{1,2}$, Aurélie Pascual ${ }^{1,2,6}$, Christelle Travaillé ${ }^{8}$, Jacques Le Bras ${ }^{4,5,6}$, Bruno Pradines ${ }^{1,2,6^{*}}$ and The French National Reference Centre for Imported Malaria Study Group

\begin{abstract}
Background: The objective of this study was to evaluate the distribution of a series of independent doxycycline inhibitory concentration $50 \%\left(I C_{50}\right)$ values to validate the trimodal distribution previously described and to validate the use of the pftetQ and pfmdt genes as molecular markers of decreased in vitro doxycycline susceptibility in Plasmodium falciparum malaria.

Methods: Doxycycline $I_{50}$ values, from 484 isolates obtained at the French National Reference Centre for Imported Malaria (Paris) between January 2006 and December 2010, were analysed for the first time by a Bayesian mixture modelling approach to distinguish the different in vitro phenotypic groups by their $\mathrm{IC}_{50}$ values. Quantitative real-time polymerase chain reaction was used to evaluate the pftetQ and pfmdt copy numbers of 89 African $P$. falciparum isolates that were randomly chosen from the phenotypic groups.

Results: The existence of at least three doxycycline phenotypes was demonstrated. The mean doxycycline $I_{50}$ was significantly higher in the group with a pftetQ copy number $>1$ compared to the group with a pftetQ copy number $=1(33.17 \mu \mathrm{M}$ versus $17.23 \mu \mathrm{M})$ and the group with a pfmdt copy number $>1$ (28.28 $\mu \mathrm{M}$ versus $16.11 \mu \mathrm{M})$. There was a significant difference between the combined low and medium doxycycline $I_{50}$ group and the high $I C_{50}$ group in terms of the per cent of isolates with one or more copy numbers of the pftetQ gene ( $0 \%$ versus 20.69\%) or pfmdt gene (8.33\% versus 37.93\%). In the logistic regression model, the pfmdt and pftetQ copy numbers $>1$ (odds ratio $=4.65$ and 11.47 ) were independently associated with the high $I C_{50}$ group.
\end{abstract}

Conclusions: Copy numbers of pftetQ and pfmdt are potential predictive molecular markers of decreased susceptibility to doxycycline.

Keywords: Malaria, Plasmodium falciparum, Anti-malarial, In vitro, Resistance, Molecular marker, Doxycycline

\footnotetext{
* Correspondence: bruno.pradines@free.fr

'Unité de Parasitologie, Institut de Recherche Biomédicale des Armées, Marseille, France

${ }^{2}$ Unité de Recherche sur les Maladies Infectieuses et Tropicales Emergentes, UM 63, CNRS 7278, IRD 198, Inserm 1095, Aix Marseille Université, Marseille, France

Full list of author information is available at the end of the article
} 


\section{Background}

Daily administration of doxycycline is currently a recommended chemoprophylactic regimen for travellers visiting malaria-endemic areas with high prevalence of chloroquine or multidrug resistance [1]. In addition, the French malaria consensus recommends quinine and doxycycline for the first-line treatment of Plasmodium falciparum severe malaria in Asia and South America. In combination with artesunate or quinine, doxycycline remains the recommendation as the second-line treatment of uncomplicated falciparum malaria or for the treatment of severe malaria as a seven-day course [2]; however, its use is limited. Prophylactic failure of doxycycline against $P$. falciparum has been associated with both inadequate doses [3] and poor compliance [4].

Since September 2002, French troops have participated in the peace-keeping operation, Operation Licorne, in the Ivory Coast. Soldiers had been prescribed doxycycline $(100 \mathrm{mg})$ daily for prophylaxis. Many cases of malaria have been reported, but most of these cases are believed to be the result of poor compliance [5,6]. From 2002 to 2006, 1,787 falciparum malaria cases were observed in French soldiers who were expected to take doxycycline. A surge in the number of malaria cases within three weeks after doxycycline prophylaxis discontinuation is often observed after return $[7,8]$. Therefore, it is recommended that doxycycline be taken for four weeks after returning from an endemic area. However, resistance can also explain failures of prophylactic doxycycline.

The ability to maximize the efficacy and longevity of anti-malarial drugs for malaria control will depend critically on intensive research to identify in vitro markers along with ex vivo and in vivo surveillance programmes. It is necessary to identify molecular markers that predict doxycycline resistance or decreased susceptibility in order that active surveillance can monitor temporal trends in parasite susceptibility [9]. Although there have been no reported clinical failures for the treatment of falciparum malaria with doxycycline, a Bayesian mixture modelling approach has distinguished three different in vitro phenotypic groups: low, medium and high doxycycline $\mathrm{IC}_{50}$ values, among 747 P. falciparum isolates obtained from 14 African countries over a nine-year period [10]. The sequences of $11 \mathrm{P}$. falciparum genes that are analogous to those involved in bacterial resistance to doxycycline were obtained from 30 isolates from each phenotypic group. The data suggested that the copy numbers of a tet $\mathrm{Q}$ GTPase family gene, pftetQ (PFL1710c), and a metabolic drug transporter gene, pfmdt (PFE0825w), were potential molecular markers of decreased in vitro susceptibility to doxycycline in African isolates [11].

The objective of this study was first to evaluate the distribution of a new series of independent doxycycline $\mathrm{IC}_{50}$ values assessed by another group for goodness of fit with the trimodal compartment model of doxycycline response previously proposed [10] and then to validate the use of the pftetQ and pfmdt genes as molecular markers of decreased in vitro susceptibility to doxycycline. This was performed by assessing the gene copy numbers in $P$. falciparum clinical isolates that were randomly chosen from the phenotypic groups with different doxycycline $\mathrm{IC}_{50}$ values.

\section{Methods}

\section{Patients and sample collection}

Between January 2006 and December 2010, 484 fresh $P$. falciparum isolates were obtained at the French National Reference Centre for Imported Malaria (Paris) from patients hospitalized with malaria after having returned to France. These samples were successfully assessed for doxycycline susceptibility. Ex vivo testing of doxycycline susceptibility was performed as previously described by a standard 42-hour ${ }^{3} \mathrm{H}$-hypoxanthine uptake inhibition assay [12]. Batches of plates were tested and validated on the chloroquine-susceptible 3D7 strain and the chloroquineresistant W2 strain.

The drug concentration that inhibited 50\% parasite growth $\left(\mathrm{IC}_{50}\right)$ was calculated with the inhibitory sigmoid Emax model, with estimation of the $\mathrm{IC}_{50}$ through nonlinear regression using a standard function of the $\mathrm{R}$ software (ICEstimator) [13].

\section{Quantification of pftetQ and pfmdt copy numbers}

pfmdt (PFE0825w) and pftetQ (PFL1710c) copy numbers were estimated by TaqMan real-time PCR (7900HT Fast Real-Time PCR system, Applied Biosystems) relative to the single-copy gene, pfßtubulin (PF10_0084). The following oligonucleotide primers and probes were designed using the Primer Express software v2.0 (Applied Biosystems) for use in the polymerase chain reactions (PCRs): 5'-TTATGCAAACATTTCAAGCTTCCT-3', 5' - ACCC ATTCCATAACTTAGATTTAGATAACC-3' and 5'-VICTAAAAACAAATTTCGACAAAAGGACAGGAGCC-TA MRA-3' for $p f m d t$, 5' -ACCCCTTTTTTATCTTACGAA AG-3', 5'-ATGGTTGTACGTTATATCATATGG-3' and 5'-VIC-AAAAATGTGGCAACAATTCAGACATGTATC A-TAMRA-3' for pftetQ and 5'-TGATGTGCGCAAGTGATCC-3', 5'-TCCTTTGTG GACATTCTTCCTC-3' and 5'-FAM-TAGCACATGCCGTTAAATATCTTCCAT GTCT-TAMRA-3' for pfßtubulin (Eurogentec). Individual PCRs were performed using $1 \mathrm{X}$ TaqMan Universal PCR Master Mix (Applied Biosystems), $900 \mathrm{nM}$ forward primer, $900 \mathrm{nM}$ reverse primer, $250 \mathrm{nM}$ TaqMan probe and $5 \mu \mathrm{L}$ template DNA in a final volume of $25 \mu \mathrm{L}$ The reaction mixtures were prepared at $4{ }^{\circ} \mathrm{C}$ in a 96-well optical reaction plate (Applied Biosystems) covered with optical adhesive covers (Applied Biosystems). The thermal cycling conditions were $50^{\circ} \mathrm{C}$ for $2 \mathrm{~min}, 95^{\circ} \mathrm{C}$ for $10 \mathrm{~min}$ and 
50 cycles of $95^{\circ} \mathrm{C}$ for $15 \mathrm{sec}$ and $60^{\circ} \mathrm{C}$ for $1 \mathrm{~min}$. Each sample was assayed in triplicate and analysed with the SDS software 2.2.1 (Applied Biosystems). The PCR efficiencies of all the primer pairs were evaluated on a dilution series of $P$. falciparum 3D7 genomic DNA. The efficiencies were found to be sufficiently close to obviate the need for any correction factor. Therefore, the $2^{-\Delta \Delta \mathrm{Ct}}$ method of relative quantification was used and adapted to estimate the number of copies of the pfindt and pftetQ genes [14,15] with the formula $\Delta \Delta \mathrm{Ct}=\left(\mathrm{Ct}_{p f m d t}-\mathrm{Ct}_{p f \beta t u b u l i n}\right)$ sample $\left(\mathrm{Ct}_{\text {pfmdt }}-\mathrm{Ct}_{\text {pfßtubulin }}\right)_{\text {calibrator. }}$ Genomic DNA extracted from 3D7 P. falciparum, which has a single copy of each gene, was used for calibration, whereas pfßtubulin served as the control housekeeping gene in all the experiments.

\section{Genetic diversity of Plasmodium falciparum isolates with pftetQ and pfmdt multicopies}

Mixed infection could influence read-out in Taqman real-time PCR, potentially leading to false positive results of gene copy number. The genomic DNA of $P$. falciparum isolates with at least two copies of pfmdt or pftetQ were investigated for genetic diversity at highly polymorphic loci, merozoite surface proteins 1 and 2 (MSP1 and MSP2). The msp1 and msp2 loci were genotyped using the nested PCR strategy and conditions previously described [16].

\section{Statistical analysis}

The statistical analysis has been designed to answer the specific question of whether $P$. falciparum has different doxycycline susceptibility phenotypes. A heterogeneous population of $\mathrm{IC}_{50}$ values was observed; therefore, the data were assumed to represent a univariate Gaussian mixture with $\mathrm{k}$ components. Each observation was assumed to originate from one of the $\mathrm{k}$ components, and the label of the group from which each observation arose was unknown. The unknowns of the model were the number of components, the means, variances and weights of the different components, and the vector of allocations of the observations. The analysis was performed in two steps. First, reversible jump Monte Carlo Markov Chains (RJMCMC) [17] samplers were used to choose a suitable number of components $k$, and the present algorithm followed the recommendations of Cappé et al. [18]. After a relevant number of components was chosen, standard Gibbs samplers were run to obtain estimates of the model parameters and to classify the observations [19]. Because of the'label-switching' problem, due to the symmetry in the likelihood of the model parameters, the mixture components should be labelled before making an inference on the parameters [20]. The classical ordering constraint, which was biologically relevant here, was used. The algorithms were run for 5,000 burn-in iterations and
20,000 post-burn-in iterations. These numbers were assumed to be sufficient to obtain reliable results. Moreover, each algorithm was run three times to check that the results between two different runs were similar and that there was no convergence problem [17].

The data were analysed using the $\mathrm{R}$ software ${ }^{\bullet}$ (version 2.10.1). The differences in the pfindt and pftetQ copy numbers between the phenotypic groups were tested using the Mann Whitney test and the Kruskal-Wallis test. The genotype proportions were compared using the Fisher exact test. The risk of the high doxycycline $\mathrm{IC}_{50}$ was analysed using a logistic regression model (univariate and multivariate analysis).

\section{Ethics}

Informed consent was not required for this study because the sampling procedures and testing are part of the French national recommendations for the care and surveillance of malaria.

\section{Results}

The doxycycline $\mathrm{IC}_{50}$ values ranged from 0.49 to $65.1 \mu \mathrm{M}$. The mean was 11.64 $\mu \mathrm{M}$ (95\% confidence interval, 10.9612.33). The average parameter estimates for the $\mathrm{IC}_{50}$ values by year are given in Table 1 .

The triple normal distribution model is represented in Figure 1. The parameter estimates for the three-component mixture model, including the number of isolates in each normal distribution, the mean of the $\mathrm{IC}_{50}$ values and the standard deviation for each distribution, are summarised in Table 2. A double normal distribution model and a quadruple normal distribution model were also fitted to the data to assess the validity of considering a three-component mixture (data not shown). These two models fit the data worse than the triple normal distribution model.

Eighty-nine $P$. falciparum isolates (30, 30 and 29) were randomly chosen from the three phenotypic groups, A, $\mathrm{B}$ and $\mathrm{C}$, that differed in their doxycycline $\mathrm{IC}_{50}$ values. These isolates were classified as follows: low doxycycline $\mathrm{IC}_{50}$ group from component A [mean, $4.33 \mu \mathrm{M}$ (95\% CI, 3.39-4.37 $\mu \mathrm{M})$ ], medium doxycycline $\mathrm{IC}_{50}$ group from component B [mean, 16.97 $\mu \mathrm{M}(95 \% \mathrm{CI}, 16.45-17.49 \mu \mathrm{M})$ ]

Table 1 Statistical analysis of the $\mathbf{4 8 4}$ doxycycline IC $_{50}$ values by year

\begin{tabular}{llllll}
\hline Year & $\mathbf{I C}_{\mathbf{5 0}}$ number & Mean $(\boldsymbol{\mu M})$ & $\mathbf{9 5 \%} \mathbf{C I}$ & $\mathbf{I C}_{\mathbf{5 0}} \mathbf{m i n}$ & $\mathbf{I C}_{\mathbf{5 0}} \mathbf{m a x}$ \\
\hline 2006 & 119 & 10.05 & $9.14-10.96$ & 0.63 & 43.7 \\
2007 & 172 & 11.91 & $10.72-13.11$ & 2.34 & 44.8 \\
2008 & 59 & 9.45 & $8.56-10.35$ & 4.27 & 23.1 \\
2009 & 40 & 12.21 & $8.01-16.41$ & 0.49 & 65.1 \\
2010 & 94 & 14.3 & $12.63-15.97$ & 4.55 & 46.2 \\
Total & 484 & 11.64 & $10.96-12.33$ & 0.49 & 65.1 \\
\hline
\end{tabular}

95\% Cl: 95\% confidence interval. 


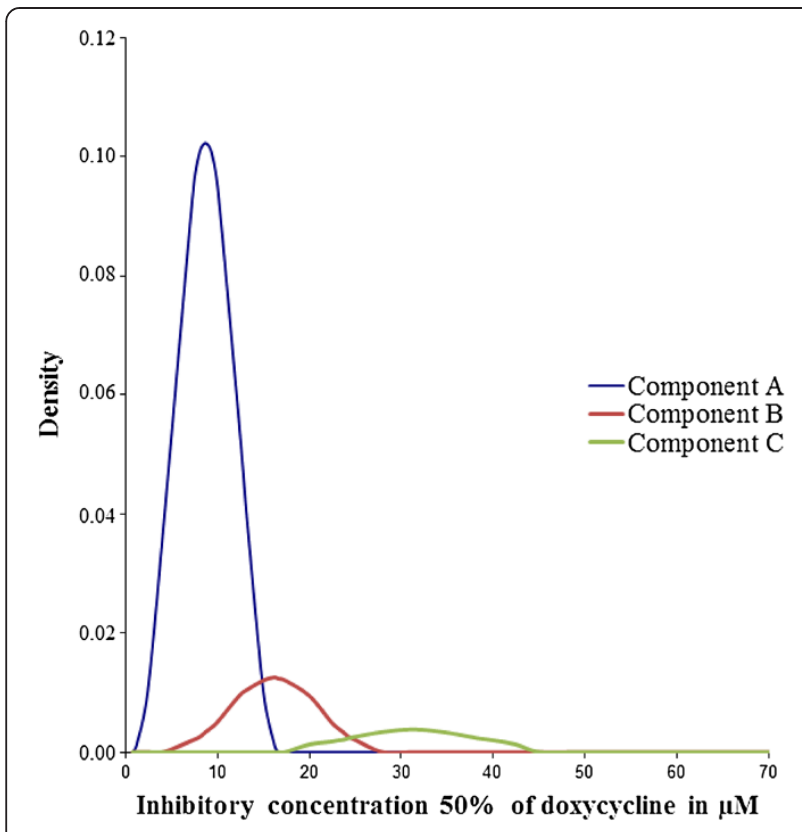

Figure 1 Distribution of the doxycycline $\mathrm{IC}_{50}$ values of the 484 Plasmodium falciparum isolates (2006 to 2010) in the threecomponent mixture model (Bayesian mixture modelling approach). The dotted lines represent the three fitted mixtures.

and high doxycycline $\mathrm{IC}_{50}$ group from component $\mathrm{C}$ [mean, 34.60 $\mu \mathrm{M}$ (95\% CI, 31.30-37.90 $\mu \mathrm{M})$ ].

Only one or two copies of $p f m d t$ and $p f t e t Q$ were identified in the 89 isolates. All of the isolates with two copies $p f m d t$ or $p f t e t Q$ had 1 allelic family for each of the two genes ( $m s p 1$ and $m s p 2)$, confirming that these infections were single and not mixed. The mean doxycycline $\mathrm{IC}_{50}$ was significantly higher in the group with a pftetQ copy number $>1$ compared to the group with a pftet $Q$ copy number $=1$ (33.17 $\mu \mathrm{M}$ versus $17.23 \mu \mathrm{M} ; P=0.0041$, Mann Whitney test) (Table 3). The mean doxycycline $\mathrm{IC}_{50}$ was significantly higher in the group with a $\mathrm{pfmdt}$ copy number $>1(28.28 \mu \mathrm{M}$ versus $16.11 \mu \mathrm{M} ; P=0.0025$, Mann-Whitney test).

The number of $p f t e t Q$ copies was significantly higher in the high doxycycline $\mathrm{IC}_{50}$ group compared to the low and medium doxycycline $\mathrm{IC}_{50}$ groups (1.21 versus 1.0 and 1.0; $P=0.0014$, Kruskal-Wallis test). The number of $p f m d t$ copies was significantly higher in the high doxycycline

Table 2 Parameter estimates for the three-component mixture model for the 484 Plasmodium falciparum isolates

\begin{tabular}{lllll}
\hline Component & Isolates number & $\begin{array}{l}\text { Proportion } \\
(\%)\end{array}$ & $\begin{array}{l}\mathrm{IC}_{\mathbf{5 0}} \\
\text { mean }(\boldsymbol{\mu} \mathrm{M})\end{array}$ & $\begin{array}{l}\text { Standard } \\
\text { deviation }\end{array}$ \\
\hline A & 393 & 81.1 & 8.70 & 2.87 \\
B & 60 & 12.4 & 16.18 & 4.86 \\
C & 31 & 6.5 & 31.23 & 10.32 \\
\hline
\end{tabular}

Table 3 Statistical analysis of the doxycycline $I_{50}$ values based on the pftetQ and pfmdt copy numbers in $\mathbf{8 9}$ Plasmodium falciparum isolates

\begin{tabular}{|c|c|c|c|c|}
\hline & \multicolumn{2}{|c|}{ pftetQ copy number } & \multicolumn{2}{|c|}{ pfmdt copy number } \\
\hline & $=1$ & $>1$ & $=1$ & $>1$ \\
\hline Number of values & 83 & 6 & 73 & 16 \\
\hline $\mathrm{IC}_{50}$ mean $(\mu \mathrm{M})$ & 17.23 & 33.17 & 16.11 & 28.28 \\
\hline Standard deviation & 13.32 & 6.85 & 12.53 & 14.03 \\
\hline $\begin{array}{l}95 \% \text { Confidence } \\
\text { interval }\end{array}$ & $14.32-20.13$ & $25.98-40.37$ & 13.19-19.04 & 20.81-35.76 \\
\hline Minimal $I C_{50}$ & 0.49 & 25.16 & 0.49 & 4.62 \\
\hline Maximal $I C_{50}$ & 65.11 & 43.7 & 44.82 & 65.11 \\
\hline
\end{tabular}

$\mathrm{IC}_{50}$ group compared to the low and medium doxycycline $\mathrm{IC}_{50}$ groups (1.38 versus 1.13 and 1.03 , respectively; $P=$ 0.0019 , Kruskal-Wallis test).

There was no significant difference between the low and medium doxycycline $\mathrm{IC}_{50}$ groups for the $p f m d t$ and pftetQ copy numbers. Therefore, these two phenotypic groups were combined. There was a statistically significant difference between the low and medium doxycycline $\mathrm{IC}_{50}$ combined group and the high doxycycline group in terms of the per cent of isolates with one or more copy numbers of the pftetQ gene ( $0 \%$ versus $20.69 \%$; $P=0.0008$, Fisher's exact test) or pfindt gene ( $8.33 \%$ versus 37.93\%; $P=0.0021$, Fisher's exact test) (Table 4 ).

In the logistic regression model (Table 5), the $p f m d t$ copy number $>1$ (adjusted $\mathrm{OR}=4.65[1.31-16.51], P=0.0176$ ) and pftet $Q$ copy number $>1$ (adjusted $\mathrm{OR}=11.47[1.23$ 106.98], $P=0.0322$ ) were independently associated with the high $\mathrm{IC}_{50}$ phenotypic group.

\section{Discussion}

Most prophylactic failures of doxycycline against $P$. falciparum are associated with the use of standard doses resulting in lower than expected serum drug levels [21], inadequate low doses [3], or poor compliance [4,22]. Moreover, doxycycline pharmacokinetic parameters could explain some of these cases. Doxycycline has a short elimination half-life (16 hours) compared to proguanil (24 hours), atovaquone (31-73 hours), chloroquine (two to

Table 4 Statistical analysis of pftetQ and pfmdt copy numbers in $\mathbf{8 9}$ Plasmodium falciparum isolates (Fisher's exact test)

\begin{tabular}{|c|c|c|c|c|}
\hline & \multicolumn{2}{|l|}{ PftetQ } & \multicolumn{2}{|l|}{ Pfmdt } \\
\hline & $\begin{array}{l}\text { Low and } \\
\text { medium } \mathrm{IC}_{50}\end{array}$ & High IC $C_{50}$ & $\begin{array}{l}\text { Low and } \\
\text { medium } \mathrm{IC}_{50}\end{array}$ & High IC 50 \\
\hline Copy number >1 & 0 & 6 & 5 & 11 \\
\hline Copy number = 1 & 60 & 23 & 55 & 18 \\
\hline$\%$ & 0.00 & 20.69 & 8.33 & 37.93 \\
\hline Fisher's exact test & $P$ value & 0.0008 & $P$ value & 0.0021 \\
\hline
\end{tabular}


Table 5 Multivariate regression model

\begin{tabular}{|c|c|c|c|c|c|c|}
\hline \multirow[b]{2}{*}{ Molecular marker } & \multicolumn{2}{|c|}{ Doxycycline $I C_{50}$ group, number } & \multirow[b]{2}{*}{ Crude OR $(95 \% \mathrm{Cl})$} & \multirow[b]{2}{*}{$P$} & \multirow[b]{2}{*}{ Adjusted OR (95\% Cl) } & \multirow[b]{2}{*}{$P$} \\
\hline & Low or medium & High & & & & \\
\hline \multicolumn{7}{|l|}{ pftetQ copy number } \\
\hline 1 & 60 & 23 & 1.00 (reference) & & 1.00 (reference) & \\
\hline$>1$ & 0 & 6 & $18.77(2.18-161.43)$ & 0.0076 & $11.47(1.23-106.98)$ & 0.0322 \\
\hline \multicolumn{7}{|l|}{ pfmdt copy number } \\
\hline 1 & 55 & 5 & 1.00 (reference) & & 1.00 (reference) & \\
\hline$>1$ & 18 & 11 & $6.72(2.06-21.96)$ & 0.0016 & $4.65(1.31-16.51)$ & 0.0176 \\
\hline
\end{tabular}

three days), or mefloquine (six to 41 days), and a short mean residence time (63\% of the administered dose is eliminated in 27 hours) [8]. In addition, its slow action in vitro has a delayed effect upon growth and requires the prolonged incubation of parasites [23]. Determination of the $\mathrm{IC}_{50}$ after two generations of parasite growth decreases the 42-hour $\mathrm{IC}_{50}$ from ten- to 20-fold [24,25]. However, in practice, the standard 42-hour test remains the method of monitoring doxycycline ex vivo susceptibility.

Maximizing the efficacy and longevity of anti-malarial drugs to control malaria will critically depend on intensive research to identify in vitro markers along with the implementation of ex vivo and in vivo surveillance programmes, such as those championed by the WorldWide Antimalarial Resistance Network [26]. Therefore, there is a need to identify molecular markers that predict doxycycline resistance, which can provide an active surveillance method to monitor temporal trends in parasite susceptibility [9]. In addition, the early detection of resistance or decreased susceptibility to doxycycline will require that the baseline parasite chemosusceptibility of current isolates from endemic regions is established.

To validate the trimodal distribution model of doxycycline $\mathrm{IC}_{50}$ values previously described for $P$. falciparum African isolates [10], the distribution of a new series of independent doxycycline $\mathrm{IC}_{50}$ values that were assessed by a separate group under the same technical conditions [12] was evaluated. This analysis was performed with a Bayesian mixture modelling approach. Again, the demonstration of the existence of at least three doxycycline phenotypes was confirmed. All 484 values were classified into three components: component $\mathrm{A}$ ( $\mathrm{IC}_{50}$ mean $\left.8.7 \mu \mathrm{M}\right)$, component $\mathrm{B}\left(\mathrm{IC}_{50}\right.$ mean $\left.16.2 \mu \mathrm{M}\right)$, and component $\mathrm{C}\left(\mathrm{IC}_{50}\right.$ mean $\left.31.2 \mu \mathrm{M}\right)$. This trimodal distribution model of doxycycline $\mathrm{IC}_{50}$ values from imported P. falciparum isolates obtained from 2006 to 2010 confirms the previous data [10]. However, the level of the $\mathrm{IC}_{50}$ value in each component is different between the series of imported P. falciparum isolates obtained from 2006 to 2010 and those obtained from 1999 to 2006 [10]. The $\mathrm{IC}_{50}$ doxycycline values from the isolates obtained from 1999 to 2006 were classified into three components: component A ( $\mathrm{IC}_{50}$ mean $\left.4.9 \mu \mathrm{M}\right)$, component $\mathrm{B}\left(\mathrm{IC}_{50}\right.$ mean $\left.7.7 \mu \mathrm{M}\right)$, and component $\mathrm{C}\left(\mathrm{IC}_{50}\right.$ mean $17.9 \mu \mathrm{M})$. It appears that components $\mathrm{A}$ and $\mathrm{B}\left(\mathrm{IC}_{50}\right.$ means $4.9 \mu \mathrm{M}$ and $7.7 \mu \mathrm{M}$, respectively) for the values obtained from 1999 to 2006 have merged into a single component $\mathrm{A}\left(\mathrm{IC}_{50}\right.$ mean $\left.8.7 \mu \mathrm{M}\right)$ for the values obtained from 2006 to 2010. In addition, the percentage of isolates (78\%) in the two components, A and B, for the values obtained from 1999 to 2006 is similar to the percentage of isolates (81\%) for component $\mathrm{A}$ for the values obtained from 2006 to 2010. The component $\mathrm{B}\left(\mathrm{IC}_{50}\right.$ mean $16.2 \mu \mathrm{M})$ values obtained from 2006 to 2010 correspond to the component $\mathrm{C}\left(\mathrm{IC}_{50}\right.$ mean $\left.17.9 \mu \mathrm{M}\right)$ values obtained from 1999 to 2006. A new component, component C ( $\mathrm{IC}_{50}$ mean $31.2 \mu \mathrm{M}$, proportion $6.4 \%$ ), emerged for the values obtained from 2006 to 2010 . These data suggest the emergence of strains with decreased susceptibility to doxycycline. In addition, based on the previously defined cut-off for reduced susceptibility to doxycycline $(35 \mu \mathrm{M})$ [10], $1.2 \%$ of the 747 P. falciparum isolates tested from 1999 to 2006 were considered to have decreased susceptibility to doxycycline versus $2.7 \%$ for the 484 isolates tested from 2006 to 2010.

Plasmodium falciparum possesses a tetQ GTPase family gene analogue of the genes that encode bacterial ribosomal protection proteins. These genes are the pftetQ, which is involved in bacterial resistance to the cycline drugs, and a multidrug transporter gene, pfmdt, which shares a high sequence identity with efflux pumps. In a multivariate logistic regression model, an increased pfindt copy number was associated with high doxycycline $\mathrm{IC}_{50}$ values with an adjusted odds ratio (OR) of 7.09 $(\mathrm{p}=0.011)$, and an increased pftet $Q$ copy number was associated with an adjusted OR of $5.23(\mathrm{p}=0.042)$ [11]. To validate the use of the pftet $Q$ and $p f m d t$ genes as molecular markers of decreased in vitro susceptibility to doxycycline by assessing the gene copy numbers, 89 (30, 30 and 29) $P$. falciparum clinical isolates were randomly chosen from the three phenotypic groups (A, B and C) with different doxycycline $\mathrm{IC}_{50}$ values. These isolates were classified as follows: low doxycycline $\mathrm{IC}_{50}$ group from component A [mean, $4.33 \mu \mathrm{M}(95 \% \mathrm{CI}, 3.39-4.37 \mu \mathrm{M})$ ], 
medium doxycycline $\mathrm{IC}_{50}$ group from component $\mathrm{B}$ [mean, $16.97 \mu \mathrm{M}(95 \% \mathrm{CI}, 16.45-17.49 \mu \mathrm{M})]$ and high doxycycline $\mathrm{IC}_{50}$ group from component $\mathrm{C}$ [mean, $34.60 \mu \mathrm{M}(95 \% \mathrm{CI}$, 31.30-37.90 $\mu \mathrm{M})$ ]. These isolates were obtained from patients hospitalized with malaria after travel in Cameroon $(\mathrm{n}=18)$, Ivory Coast $(\mathrm{n}=14)$, Mali $(\mathrm{n}=11)$, Niger $(\mathrm{n}=5)$, Burundi $(\mathrm{n}=4)$, Burkina Faso $(\mathrm{n}=4)$, Djibouti $(\mathrm{n}=4)$, Madagascar $(n=4)$, Congo $(n=5)$, Ghana $(n=3)$, Sudan $(\mathrm{n}=2)$, Central African Republic $(\mathrm{n}=2)$, Zambia $(\mathrm{n}=1)$, Rwanda $(\mathrm{n}=1)$, Togo $(\mathrm{n}=1)$, Guinea $(\mathrm{n}=1)$, and nine from Africa without specificity regarding the country.

The mean doxycycline $\mathrm{IC}_{50}$ value is significantly higher in the groups with pftetQ or pfmdt copy numbers $>1$, suggesting that pftetQ and $p f m d t$ could be involved in the reduced susceptibility to doxycycline.

The number of pftet $Q$ and $p f m d t$ gene copies is significantly higher in the high doxycycline $\mathrm{IC}_{50}$ group than the low and medium doxycycline $\mathrm{IC}_{50}$ groups. However, there is no significant difference between the low and the medium doxycycline $\mathrm{IC}_{50}$ groups for the $p f m d t$ and $p f t e t Q$ copy numbers. These two phenotypic groups were, therefore, combined. There is a statistically significant difference between the low and medium doxycycline $\mathrm{IC}_{50}$ combined group and the high doxycycline group in terms of the per cent of isolates with one or more copy numbers of the pftet $Q$ gene $(0 \%$ versus $20.69 \%$; $P=0.0008)$ or $p f m d t$ gene $(8.33 \%$ versus $37.93 \% ; P=0.0021)$. In addition, in the multivariate logistic regression model, an increased $p f m d t$ copy number is associated with high doxycycline $\mathrm{IC}_{50}$ values with an adjusted OR of $4.65(P=0.0176)$, and an increased $p f t e t Q$ copy number is associated with an adjusted OR of $11.47(P=0.0322)$. These results are consistent with previous data [11] and confirm the potential use of $p f t e t Q$ and $p f m d t$ as predictive molecular markers for decreased $P$. falciparum susceptibility to doxycycline in Africa.

In a study on fresh $P$. falciparum clinical isolates from Dakar, Senegal, it was shown that there was no statistically significant difference between a group with a doxycycline $\mathrm{IC}_{50}<25 \mu \mathrm{M}$ and a group with an $\mathrm{IC}_{50}>25 \mu \mathrm{M}$ in terms of the per cent of isolates with one or more copy numbers of the pftet $\mathrm{Q}$ gene $(\mathrm{p}=0.079)$ or $p f m d t$ gene $(\mathrm{p}=0.066)$ [27]. However, the significance levels of these associations were just above the $P$ value threshold $(0.05)$. It seems that the number of isolates from the high doxycycline $\mathrm{IC}_{50}$ group (15.9\%) was most likely too low to obtain statistically significant differences, indicating the necessity of assessing the gene copy numbers with more isolates. Another possibility is that over-expression of pftetQ or pfmdt could confer in vitro reduced susceptibility to doxycycline in association with other contributing determinants, which could modulate the in vitro response to doxycycline.

In summary, this study demonstrates that copy numbers of the pftetQ and pfindt genes are potential predictive molecular markers of decreased P. falciparum susceptibility to doxycycline in Africa. Epidemiological studies using large numbers of parasites with reduced susceptibility to doxycycline are now required to determine whether $p f t e t Q$ and pfmdt can be used as markers of reduced in vitro doxycycline susceptibility.

\section{Competing interests}

The authors have declared that they have no competing interests.

\section{Authors' contributions}

TG, NW, ML and AP carried out the molecular genetic studies. SH, VH and JLB carried out the ex vivo evaluation of doxycycline susceptibility. The French National Reference Centre for Imported Malaria Study Group supervised, carried out and coordinated the field collections of patient isolates. $\mathrm{BP}$ and $\mathrm{SB}$ conceived and coordinated the study. SB, MB, CT and BP analysed the data. TG, SB, SH, MB, JLB and BP drafted the manuscript. All the authors read and approved the final manuscript.

\section{Authors' information}

French National Reference Centre for Imported Malaria Study Group: A Aboubacar (CHU Strasbourg), Agnamey P. (CHU Amiens), Ajana F. (CH Tourcoing), Amal C. (CH Mourier, Colombes), Amira R. (CHG Saint Denis), Argy N. (CHU Bichat-Claude Bernard, Paris), Baumard S. (CHRU Reims), Bellanger A. P. (CHU Minjoz, Besancon), Bemba D. (CH Verdier, Bondy), Beytout J. (CHRU Clermont Ferrand), Bigel M.L. (CH Quesnay, Mante la Jolie), Bloch M. (CH Mourier, Colombes), Bonnet R. (CHRU Clermont Ferrand), Borel A. (CHU Amiens), Bouchaud O. (CH Avicenne, Bobigny), Branger C. (CH Mourier, Colombes), Bruneel F. (CH Mignot, Versailles), Cambon M. (CHRU Clermont Ferrand), Camus D. (CH Lille), Casalino E. (CHU Bichat-Claude Bernard, Paris), Clain J. (CHU Bichat-Claude Bernard, Paris), Cojean S. (CHU Bichat-Claude Bernard, Paris), Cuisenier B. (CHU Dijon), De Gentile L. (CHU Angers), Delarbre J. M. (CH Moenchsberg, Mulhouse), Delaval A. (CH Balanger, Aulnay sous Bois), Durand R. (CH Avicenne, Bobigny), Dutoit E. (CH Lille), Eloy O. (CH Mignot, Versailles), Faucher J. F. (CHU Minjoz, Besancon), Faye A. (CH Debre, Paris), Fenneteau O. (CH Debre, Paris), Filisetti D. (CHU Strasbourg), Fulleda C. (CHU Lariboisiere, Paris), Godineau N. (CHG Saint Denis), Grenouillet F. (CHU Minjoz, Besancon), Hurst J. P. (CH Monod, Le Havre), Ichou H. (CH Mourier, Colombes), Klein E. (CHU Lariboisiere, Paris), Lariven S. (CHU Bichat-Claude Bernard, Paris), Lefevre M. (CH Laennec, Creil), Lemoine M. (CHU Bichat-Claude Bernard, Paris), Lesens O. (CHRU Clermont Ferrand), Lohmann C. (CH Moenchsberg, Mulhouse), Lusina D. (CH Balanger, Aulnay sous Bois), Machouart M. C. (CHR Nancy), Mary R. (CHG Saint Denis), Matheron S. (CHU Bichat-Claude Bernard, Paris), Mechali D. (CHG Saint Denis), Merrens A. (HIA Begin, Saint Mande), Millon L. (CHU Minjoz, Besancon), Monnier S. (CH Mignot, Versailles), Mortier E. (CH Mourier, Colombes), Moussel F. (CH Quesnay, Mante la Jolie), Pageot L. (CHU Bichat-Claude Bernard, Paris), Parez N. (CH Mourier, Colombes), Patoz P. (CH Tourcoing), Pfaff A. (CHU Strasbourg), Pihet M. (CHU Angers), Pilo J. E. (HIA Begin, Saint Mande), Poilane I. (CH Verdier, Bondy), Pons D. (CHRU Clermont Ferrand), Poupart M. (CHG Saint Denis), Prevel M. (CHG Saint Denis), Pull L. (CH Debre, Paris), Rapp C. (HIA Begin, Saint Mande), Rivier A. (CHR Nancy), Ronez E. (CHU Lariboisiere, Paris), Rotten D. (CHG Saint Denis), Sarrasin V. (CHU Bichat-Claude Bernard, Paris), Silva M. (CH Monod, Le Havre), Simonet A. L. (CHU Dijon), Siriez J. Y. (CH Debre, Paris), Strady C. (CH Debre, Reims), Therby A. (CH Mignot, Versailles), Thibault M. (CH Dubos, Cergy Pontoise), Thouvenin M. (CH Troyes), Toubas D. (CHRU Reims).

\section{Acknowledgements}

This study was supported by the Institut de Veille Sanitaire (grant number CNR paludisme) and the Délégation Générale pour l'Armement (grant number 10C0405)

\section{Author details}

'Unité de Parasitologie, Institut de Recherche Biomédicale des Armées, Marseille, France. ${ }^{2}$ Unité de Recherche sur les Maladies Infectieuses et Tropicales Emergentes, UM 63, CNRS 7278, IRD 198, Inserm 1095, Aix Marseille Université, Marseille, France. ${ }^{3}$ Fédération des Laboratoires, Hôpital d'Instruction des Armées Saint Anne, Toulon, France. ${ }^{4}$ Laboratoire de Parasitologie-Mycologie, Hôpital Bichat-Claude Bernard, Paris, France. ${ }^{5}$ Unité 
Mixte de Recherche 216 IRD, Université Paris Descartes, Paris, France. ${ }^{6}$ Centre National de Référence du Paludisme, Paris, France. ${ }^{7}$ Unité de Recherche Mixte Sup-Agro-Inra MISTEA, SupAgro, Montpellier, France. ${ }^{8}$ Unité de Recherche Mixte MD3, Institut de Recherche Biomédicale des Armées, Marseille, France.

Received: 2 July 2013 Accepted: 10 November 2013 Published: 14 November 2013

\section{References}

1. Société de Pathologie Infectieuse de Langue Française, Collège des Universitaires de Maladies Infectieuses et Tropicales, Société de Médecine des Armées, Société Française de Parasitologie, Société Française de Pédiatrie, Société de Médecine des Voyages, Société de Pathologie Exotique, Société de Réanimation de Langue Française: Management and prevention of imported Plasmodium falciparum malaria: recommendations for clinical practice 2007 (revision 2007 of the 1999 consensus conference). Med Mal Infect 2008, 38:68-117.

2. World Health Organization: WHO guidelines for the treatment of malaria. 2nd edition. Geneva: WHO Press; 2010

3. Pang L, Limsomwong N, Singharaj P: Prophylactic treatment of vivax and falciparum malaria with low-dose doxycycline. J Infect Dis 1988, 158:1124-1127

4. Wallace MR, Sharp TW, Smoak B, Iriye C, Rozmajzl P, Thornton SA, Batchelor R, Magill AJ, Lobel HO, Longer CF, Burans JP: Malaria among United States troops in Somalia. Am J Med 1996, 100:49-55.

5. Migliani R, Josse R, Hovette R, Keundjian A, Pages F, Meynard JB, Ollivier L, Sbai Idrissi K, Tifratene K, Orlandi E, Rogier C, Boutin JP: Le paludisme vu des tranchées: le cas de la Côte d'Ivoire en 2002-2003. Med Trop 2003, 63:282-286

6. Migliani R, Ollivier L, Romand O, Verret C, Haus-Cheymol R, Todesco A, Pagès F, Pradines B, Queyriaux B, Texier $G$, Michel $R$, Spiegel A, Boutin JP: Paludisme chez les militaires français en Côte d'Ivoire de 1998 à 2006. Bull Epidemiol Hebdom 2008, 23-24:209-212.

7. Pang LW, Limsomwong N, Boudreau EF, Singharaj P: Doxycycline prophylaxis for falciparum malaria. Lancet 1987, i:1161-1164

8. Shmuklarsky MJ, Boudreau EF, Pang LW, Smith JI, Schneider I, Fleckenstein L, Abdelrahim MM, Canfield CJ, Schuster B: Failure of doxycycline as a causal prophylactic agent against Plasmodium falciparum malaria in healthy nonimmune volunteers. Ann Int Med 1994, 120:294-299.

9. Plowe CV, Roper C, Barnwell JW, Happi CT, Joshi HH, Mbacham W, Meshnick SR, Mugittu K, Naidoo I, Price RN, Shafer RW, Sibley CH, Sutherland CJ, Zimmerman PA, Rosenthal PJ: World antimalarial resistance network (WARN). III: molecular markers for drug resistant malaria. Malar J 2007, 6:121

10. Briolant S, Baragatti M, Parola P, Simon F, Tall A, Sokhna C, Hovette P, Mamfoumbi MM, Koeck JL, Delmont J, Spiegel A, Castello J, Gardair JP, Trape JF, Kombila M, Minodier P, Fusai T, Rogier C, Pradines B: Multinormal in vitro distribution model suitable for the distribution of Plasmodium falciparum chemosusceptibility to doxycycline. Antimicrob Agents Chemother 2009, 53:688-695.

11. Briolant S, Wurtz N, Zettor A, Rogier C, Pradines B: Susceptibility of Plasmodium falciparum isolates do doxycycline is associated with pftetQ sequence polymorphisms and pftetQ and pfmdt copy numbers. J Infect Dis 2010, 201:152-159

12. Parola P, Pradines B, Simon F, Carlotti MP, Minodier P, Ranjeva MP, Badiaga S, Bertaux L, Delmont J, Morillon M, Silai R, Brouqui P, Parzy D: Antimalarial drug susceptibility and point mutations associated with resistance in 248 Plasmodium falciparum isolates imported from Comoros to Marseille. Am J Trop Med Hyg 2007, 77:431-437.

13. Le Nagard $H$, Vincent $C$, Mentré $F$, Le Bras J: Online analysis of in vitro resistance to antimalarial drugs through nonlinear regression. Comput Methods Programs Biomed 2011, 104:10-18.

14. Livak KJ, Schmittgen TD: Analysis of relative gene expression data using real-time quantitative PCR and the 2(-Delta Delta $C(T))$ Method. Methods 2001, 25:402-408.

15. Ferreira ID, Rosario VE, Cravo PV: Real-time quantitative PCR with SYBR Green I detection for estimating copy numbers of nine drug resistance candidate genes in Plasmodium falciparum. Malar J 2006, 5:1

16. Henry M, Diallo I, Bordes J, Ka S, Pradines B, Diatta B, M'Baye PS, Sane M, Thiam M, Gueye PM, Wade B, Touze JE, Debonne JM, Rogier C, Fusai T: Urban malaria in Dakar, Senegal: chemosusceptibility and genetic diversity of Plasmodium falciparum isolates. Am J Trop Med Hyg 2006, 75:146-151.

17. Richardson S, Green PJ: On Bayesian analysis of mixtures with an unknown number of components (with discussion). J Roy Stat Soc 1997, B59:731-792.

18. Cappé O, Robert CP, Rydén T: Reversible jump, birth-and-death and more general continuous time Markov chain Monte Carlo samplers. J Roy Stat Soc 2003, B65:679-700

19. Diebolt J, Robert CP: Estimation of finite mixture distributions through Bayesian sampling.J Roy Stat Soc 1994, 56:363-375.

20. Jasra A, Holmes CC, Stephens DA: Markov chain Monte Carlo methods and the label switching problem in Bayesian mixture modeling. Statistical Science 2005, 20:50-67.

21. Weiss WR, Oloo AJ, Johnson A, Koech D, Hoffman SL: Daily primaquine is effective for prophylaxis against falciparum malaria in Kenya: comparison with mefloquine, doxycycline, and chloroquine plus proguanil. J Infect Dis 1995, 171:1569-1575.

22. Shanks GD, Roessler P, Edstein M, Rieckmann KH: Doxycycline for malaria prophylaxis in Australian soldiers deployed to United Nations missions in Somalia and Cambodia. Mil Med 1995, 160:443-444.

23. Dahl EL, Rosenthal PJ: Multiple antibiotics exert delayed effects against the Plasmodium falciparum apicoplast. Antimicrob Agents Chemother 2007, 51:3485-3490

24. Pradines B, Spiegel A, Rogier C, Tall A, Mosnier J, Fusai T, Trape JF, Parzy D: Antibiotics for prophylaxis of Plasmodium falciparum infections: in vitro activity of doxycycline against Senegalese isolates. Am J Trop Med Hyg 2000, 62:82-85.

25. Pradines B, Rogier C, Fusai T, Mosnier J, Daries W, Barret E, Parzy D: In vitro activities of antibiotics against Plasmodium falciparum are inhibited by iron. Antimicrob Agents Chemother 2001, 45:1746-1750.

26. Sibley $\mathrm{CH}$, Barnes KI, Watkins WM, Plowe CV: A network to monitor antimalarial drug resistance: a plan for moving forward. Trends Parasitol 2008, 24:43-48.

27. Gaillard T, Fall B, Tall A, Wurtz N, Diatta B, Lavina M, Fall KB, Sarr FD, Baret E, Diémé $Y$, Wade $B$, Bercion R, Briolant $S$, Pradines B: Absence of association between ex vivo susceptibility to doxycycline and pftetQ and pfmdt copy numbers in Plasmodium falciparum isolates from Dakar, Senegal. Clin Microbiol Infect 2012, 18:E238-E240.

doi:10.1186/1475-2875-12-414

Cite this article as: Gaillard et al:: PftetQ and pfmdt copy numbers as predictive molecular markers of decreased ex vivo doxycycline susceptibility in imported Plasmodium falciparum malaria. Malaria Journal 2013 12:414.

\section{Submit your next manuscript to BioMed Central and take full advantage of:}

- Convenient online submission

- Thorough peer review

- No space constraints or color figure charges

- Immediate publication on acceptance

- Inclusion in PubMed, CAS, Scopus and Google Scholar

- Research which is freely available for redistribution 